\title{
Sakip Evaluation Based on Performance Management Based on Balanced Scorecard Secretariat Organization Regional Bureau South Kalimantan Province
}

\author{
Galih Yudhi Permana*, Samahuddin Muharam, Muhammad Riduansyah Syafari
}

Master Program of Government Science, Lambung Mangkurat University, Banjarmasin, Indonesia

\author{
DOI: $10.36348 /$ sijlcj.2019.v02i11.005 $\quad$ | Received: 08.11.2019| Accepted: 15.11 .2019 | Published: 19.11 .2019 \\ *Corresponding author: Galih Yudhi Permana
}

\section{Abstract}

This study aims to determine how the implementation of the Government Performance Accountability System (SAKIP) was evaluated based Performance Management Balanced Scorecard. Impact of the implementation of the Government Performance Accountability System in improving the performance of all employees at the Bureau Secretariat Organization of South Kalimantan Province. The research was conducted using a qualitative descriptive study, through interviews with sources and conduct performance document related documentation. The data analysis technique used in this study is that the data reduction, data display, and conclusion drawing/verification. The result is the implementation of the planning performance, especially in the process of leveling performance, Among the Balanced Scorecard SAKIP there are differences in how the preparation, which uses four perspectives SAKIP not used the Balanced Scorecard. Besides the preparation of programs and activities in SAKIP can only specify a defined set of activities, without being able to choose a program that will be implemented. The process of measuring, reporting, evaluation, and monitoring of similar performance between SAKIP and Balanced Scorecard. The impact caused by the implementation of the Bureau Organization SAKIP that there is an increased achievement of good performance on the customer perspective, Finance, and Internal Processes. But for the Learning and Growth perspective still does not have a significant impact.

Keywords: Evaluation SAKIP, Balanced Scorecard.

Copyright @ 2019: This is an open-access article distributed under the terms of the Creative Commons Attribution license which permits unrestricted use, distribution, and reproduction in any medium for non-commercial use (NonCommercial, or CC-BY-NC) provided the original author and source are credited.

\section{INTODUCTION}

Ministry of Administrative Reform and Bureaucratic Reform build an integrated performance management system called Performance Accountability System for Government Agencies (SAKIP). SAKIP is a performance management system which is a modification of the strategic management based on the Balanced Scorecard. Applications based on the Balanced Scorecard strategic management becomes SAKIP to ensure the creation of comprehensive performance management of civil servants and scalable, with a record SAKIP applied following the existing guidelines.

SAKIP formed to be a system that is used as a tool to describe the performance that should exist in an SKPD. SAKIP divided into components Performance Planning, Performance Measurement, Performance Reporting, Internal Evaluation, and Performance Achievement. SAKIP designed to assist the Government in planning and measuring performance, collect and process performance data, reporting and evaluating the performance that should exist to increase performance in an integrated manner, as well as link performance with the available budget.

SAKIP excess compared with the previous planning system that is the performance planning process to synchronize between the strategic planning to the programs and activities to be implemented. By translating the vision into a regional head of mission objectives, targets and indicators of achievement are added, then the success of the vision and mission of regional heads can be calculated. With the translation of goals into indicators of achievement, the program and activities required for achieving the vision and mission can be identified accurately, so in addition to the right target, the amount disbursed budget can be adjusted. By setting a measurable target indicator, the organization's performance and the individual performance can be calculated by real value and can be seen as the results. 
The major challenge in the implementation of the Balanced Scorecard-based management strategy, in this case, SAKIP. The management style is determined by three main factors, namely toolset, mindset, and skillset, which means that the challenges faced in the management strategy of rotating on three factors. Toolset or the measuring instrument is already no longer a problem, because of the strategic management based on the Balanced Scorecard has been proven to be a management tool is effective in improving performance, both personal performance and the performance of the organization, so SAKIP as an application of strategic management based on the Balanced Scorecard will no doubt be a good management tool. The main problem lies in the mindset (the mindset) and skillset (competence) of the apparatus, in this case, a civil servant.

The commencement of a new round of midterm planning period of three South Kalimantan Province, the Provincial Government, and SKPD started back in strategic planning for the period 2016-2021. A strategic plan was drawn up tailored to the vision and mission of the new leader of South Kalimantan province concerning the Regional Long Term Plan
(RPJPD) South Kalimantan Province 2005-2025. The planning begins with the preparation of the Medium Term Development Plan (RPJMD) South Kalimantan Province from 2016 to 2021, which was subsequently integrated into the Strategic Plan (Plan) SKPD. Sector plans will become a reference in the implementation of the activities during the years 2016-2021 SKPD.

As SKPD builds on the administration SAKIP, Bureau organization should be an example and pioneer of SAKIP ideal. Implementation SAKIP (ideal) measured by the availability of planning documents (Strategic Plan (Plan), Work Plan (Renja), as well as the Work Plan Budget (RKA)) suite and have described the performance "which should". SAKIP Implementation Organization Bureau still has not shown that the ideal conditions, a trend to decrease. This is partly evidenced by the results of the evaluation by the Implementation Organization Bureau SAKIP in the period 2014 - 2015 organized by the South Kalimantan Provincial Inspectorate. But in 2016 the achievement of the evaluation results of Organization SAKIP increased back. The results of these evaluations are presented in the following table:

Table-1: Results of Evaluation Organization Bureau SAKIP Year 2014-2016

\begin{tabular}{|c|l|c|c|c|c|c|c|}
\hline \multirow{2}{*}{ No. } & \multirow{2}{*}{ Assessment } & \multicolumn{2}{c|}{$\mathbf{2 0 1 4}$} & \multicolumn{2}{c|}{$\mathbf{2 0 1 5}$} & \multicolumn{2}{c|}{$\mathbf{2 0 1 6}$} \\
\cline { 3 - 7 } & & Weight & Score & Weight & Score & Weight & Score \\
\hline 1 & performance planning & 35 & 27.46 & 30 & 25.61 & 30 & 25.19 \\
\hline 2 & performance measurement & 20 & 14.92 & 25 & 15.31 & 25 & 19.69 \\
\hline 3 & performance reporting & 15 & 11.75 & 15 & 9.95 & 15 & 10.69 \\
\hline 4 & Internal evaluation & 10 & 6,92 & 10 & 6.27 & 10 & 6.56 \\
\hline 5 & performance Achievement & 20 & 15.18 & 20 & 10.98 & 20 & 16.50 \\
\hline & Total & 100 & 76.23 & 100 & 68.12 & 100 & 78.63 \\
\hline & Category & A & & B & & BB \\
\hline
\end{tabular}

Source: Performance Report Inspectorate South Kalimantan Province, 2017

The above table shows that the condition of the Organization Bureau SAKIP is not at the level of "good", only up to the level of "Good". Those values indicate that by 2015 an internal performance management Organization Bureau has decreased in almost all components SAKIP. Supposedly, as SKPD Trustees SAKIP, Organization Bureau is expected to have first implement SAKIP in conditions that are at least close to the ideal. But ultimately back Organization Bureau can improve its performance management as evidenced by the results of the evaluation of SAKIP 2016.

Unsynchronized their role as a builder of Organization SAKIP SAKIP province with the performance of the implementation of its own would be a problem that needs to be investigated further. Supposedly as a builder, Organization Bureau ascertains the implementation SAKIP weaknesses and swiftly to fix it so that at least the implementation of the Organization Bureau SAKIP following existing standards. 2016 a change of leadership in the government of South Kalimantan. Substitution Regional Head is then followed by the turn of the formation of structural officials throughout SKPD. 2017 implemented changes in the nomenclature of organization/SKPD become the new nomenclature following government affairs contained in Act 23 of 2014 on Regional Government.

Such changes have an impact on the alternation of mostly officials who occupy positions in the Bureau of the Organization and resulted in the need for revision of the Strategic Plan SKPD implemented to adjust to the new organizational nomenclature. This revision of the entire process of establishing the Strategic Goals Organization Bureau will start again from the beginning, mainly to adjust to the Regional Head of Strategic Objectives listed in RPJMD. In other words, the process of cascading performance reimplemented in 2017 to adjust the nomenclature of the new organization. It should be an opportunity to revise 
it can be used to improve the delivery SAKIP Organization Bureau following the standard.

\section{RESEARCH METHODS}

The approach used in this study is a qualitative approach, due to testing a science/theory of the phenomenon that occurs more appropriate to use a qualitative approach that is quite loose and holistic [1]. This approach is used to answer the questions in advance so that the empirical understanding of the phenomenon of performance management more deeply Organization Bureau, to conduct observations and interviews directly to the informant. The research was conducted aiming to collect information about testing a truth to understand the phenomenon. For scientific research meets scientific requirements, the methods used must be a scientific method that describes the characteristics of science, namely the systematic, rational and empirical [2].

The focus of research is needed to establish a focus, assist in the implementation of study/research with a focus on research with the basic theories that problems outside the research are not mixed. The focus of research is useful for the evaluation of information in accordance SAKIP the Balanced Scorecard performance management based on the organizational bureau. The sampling technique used is the purposive sample, ie the sample selection based on the characteristics or properties of the previously known informant to obtain complete and sufficient information by using the principles of suitability and adequacy [1]. Informants are people who know all the ins and outs of the problem being studied. Informants in this study divided into two main informants and informants support a total of 20 people [3].

Data collected, among other things: 1) The indepth interview and structured interview to the informant by using interview, 2) observation by observation of participation (Participant observation) to observe the implementation of SAKIP conducted by the Organization Bureau, 3) documentation relating to focus on the issues of accountability and performance management performance. Data analysis was performed to describe, explain and describe the real situation then the results are interpreted in the form of a scientific article. The data analysis technique is an activity in which data analysis 1) Data Reduction summarizes the form, choose the basic things, focus on the important subject, 2) Data Display to understand what is happening with narrative text, 3) Conclusion Drawing / verification aims to provide a clearer picture of the results of research and concrete. The validity of the data used to test the data obtained during the study. Test the validity of the data is done by several steps, among others: 1) Extension of observation, 2) Improve perseverance, 3) Triangulation; sources, techniques, time, 4) member check [3, 4].

\section{RESULTS AND DISCUSSION Performance Planning}

In evaluating the Government Performance Accountability System based on the Balanced Scorecard performance management based on the Bureau of the Secretariat of the Organization of South Kalimantan Province is focused on how the Bureau Organization of planning performance and leveling performance. Before performing the comparison with the Balanced Scorecard, first organized performance management model based organization Bureau Balanced Scorecard. Preparation of the Balanced Scorecard (BSC) was built to be the basis for strategy execution. All organizations, both the private sector and the public sector will develop a strategy to achieve the goal of the establishment of the organization. But the execution of the strategy that will make a difference in the achievement of each organization's presence in the organizational difficulties executing these strategies, the BSC appears to be the solution to translate strategy into a more technical perspective. In preparing the BSC, in general, five steps must be passed, quoted by the Organizational Performance Management System was developed by the Institute of Public Administration [5], namely:

\section{The formulation of strategies \\ Determining Vision, Mission, and Strategic Goals}

In preparing the Balanced Scorecard is a nonprofit organization, the first thing that must be considered is the purpose of the organization's existence. SKPD established to help achieve the vision and mission that has been determined by the Head of Region, both in the long term, medium and short. The vision and the mission will provide a clear direction SKPD implementation because there must be a public organization to carry out the greater goal [6]. Thus the mission was placed at the top level in the Balanced Scorecard and used as a source on the translation of its organizational Balanced Scorecard. The mission that will be placed at the highest level Balanced Scorecard can be determined by identifying the organization's main concerns. The mission formulated to be specific, clear, and understandable so that the implementation can be done as directed. In SAKIP implementation, the preparation of Vision, Mission, and Objectives of Regional Head has been implemented by the leadership to be coordinated by the Regional Development Planning Agency (Bappeda). In 2018, enacted a rule that SKPD no longer has a Vision and Mission but SKPD shall state the vision and mission of the Regional Head correlated with their duties and functions. It is becoming more mainstream for SKPD which holds directly the task of implementation of Regional Head performance indicators as outlined in the Medium Term Development Plan (RPJMD). SKPD enforced the rule that no longer has a Vision and Mission but SKPD shall state the vision and mission of the Regional Head correlated with their duties and functions. It is becoming more mainstream for SKPD which holds 
directly the task of implementation of Regional Head performance indicators as outlined in the Medium Term Development Plan (RPJMD). SKPD enforced the rule that no longer has a Vision and Mission but SKPD shall state the vision and mission of the Regional Head correlated with their duties and functions. It is becoming more mainstream for SKPD which holds directly the task of implementation of Regional Head performance indicators as outlined in the Medium Term Development Plan (RPJMD).

\section{Strategic Goal Setting}

Following the results of the study on the strategic objectives of each perspective is as follows:

Table-2: Strategic Objectives of Organization

\begin{tabular}{|c|c|c|}
\hline No. & Perspective & Strategic target \\
\hline 1. & Customer perspective & $\begin{array}{l}\text { a) The formation of an ideal institutional SKPD. } \\
\text { b) Improving Accountability South Kalimantan province. } \\
\text { c) Improving the quality of public services in South } \\
\text { Kalimantan province. }\end{array}$ \\
\hline 2. & Financial perspective & a) Effectiveness and Efficiency of Use of Budget \\
\hline 3. & Internal Process Perspective & $\begin{array}{l}\text { a) Reliable availability management system } \\
\text { b) Achieving Improved Organizational Performance } \\
\text { c) Innovation in the field of organizational development. }\end{array}$ \\
\hline 4. & Learning and Growth perspective & $\begin{array}{l}\text { a) Upgrades / Employee Insights } \\
\text { b) PNS Performance Improvement Organization Bureau }\end{array}$ \\
\hline
\end{tabular}

\section{Building a Strategy Map and relationships of cause and effect}

Considering the strategy developed, the next step is to create a strategy map and establishing a causal link. The causal link is built will show the relevance and contribution of each target to the other target. This association will maintain their logical linkages as well as the consistency of their respective strategic objectives. However, the preparation of the Strategic Map Balanced Scorecard is very different between the private sector and the public sector. This is caused by the main objectives of each organization, in which the private sector has the primary objective is to maximize the benefits of the organization, while the public sector financial perspective is not the goal but rather a resource that should be streamlined and licensed.

1) Move the financial perspective to the bottom of the map. This is following the above explanation which is one of the only financial resources for the public sector to be able to achieve its strategic objectives.

2) The main purpose of the public sector is providing services to the stakeholders, including the public, the government or certain communities. Therefore, the customer's perspective is placed at the top of the map.

3) The other two perspectives are placed like in the beginning, since neither the private sector nor the public sector still needs to build up internal processes, human resources and information as well [5].

The planning process at the Bureau of Organization which is one SKPD are generally easier for the regional planning that has been carried out by the Planning Agency. SKPD stay based on the regional planning so that half of the planning itself has been resolved. The next step is to translate the regional planning into the planning organization. Referring to the local government planning set out in the Medium Term Development Plan (RPJMD), Bureau of Organization mission to two: "Delivering Governance YangProfessionalAnd Oriented On Public Service "and the goal of" Achieving Good Governance ". To achieve the mission and goals of the Organization Bureau refers to the goal of "Realization of Government Personnel Professional and Accountable Government" LAKIP performance indicators. Thus, the appropriate duties and functions of the Organization Bureau, the leveling is done specifically will refer to the achievement of targets and indicators.

In doing a performance, strategic planning who try setting goals and strategic initiatives of the translation of the vision, mission, and goals of the organization or institution of higher [7]. The formulation of this strategic objective will be the benchmark in the development of programs and activities to be implemented. The visually mapping strategy became a chart of "cause-effect" that helps the organization understand the strategy used in more depth, thus improving performance significantly. Therefore, they invented the performance tree. Trees performance in South Kalimantan provincial government began to be made in early 2016 as the implementation of the Regulation of the Minister of Administrative Reform and Bureaucratic Reform of the Republic of Indonesia Number 53 of 2014 Regarding Guidance Performance Agreement, Performance Reporting, and Procedures for the Review of the Reports Government Performance. In the process, the Tree Performance Organization Bureau has been repeatedly amended to adjust the organizational nomenclature changes. Preparation of performance Trees involves all structural and Organization Bureau employee to describe the performance becomes a "declaration of performance", and poured in a chart that has a connectedness. 
Differences were seen from the chart Trees Performance with Balanced Scorecard Strategy Map is more performance depicts a tree "hierarchy measures of performance "than the Strategic Map. The strategic map depicts a collection of organizational strategies to achieve their goals and connect to a system of causality. A strategy map depicts the organizational level and in the process becomes more technical elaboration, it is necessary to map a new strategy that is also connected with the upper-level Strategy Map. Trees contain performance targets entire perspective as the Balanced Scorecard, but the perspective targets scattered at various levels of office. This is as described above that the customer's perspective is usually included in the second echelon, financial perspective and the perspective of Internal Business apply to all levels and all the officials so that the two perspectives are common to all of them. Perspective Learning \&

\section{Preparation of Performance Indicators for Each Goal}

After the preparation of the strategy, the map was completed following the causal relationship to each target, then the next step is to determine the performance indicators for each goal with the aim that the success of each target can be measured and can focus more on the achievement of individual targets. A good performance indicator must meet several requirements, ie Specific, Measurable, Achievable, Relevant, Time-bounded, and continuously shortened SMART-C. Specific indicators organized means to be clear and not multi interpretation, Measurable means can be measured both qualitatively and quantitatively, Achievable means that can be achieved (not something too hard), Relevant means in conformity with the vision, mission, and target.

In the preparation of indicators, note that the indicators that are based on past data are sometimes not enough to evaluate performance, but also required another predictive indicator. The indicators are based on past data with an indicator called "lagging" indicator predictive and referred to the indicators of the "leading". Balanced Scorecard will be perfect when it contains both kinds of indicators, because it is too struggling with a "past" will not provide information about how the daily work carried out, and if it is too fixated on leading indicators will be difficult to assess whether remedial efforts made an impact on the organization [6]. The lagging indicator provides information on the performance,

Furthermore, performance indicators should be accompanied by targets, both short-term targets (annual), medium-term (5 years) and long term (20/25 years or more). In some literature also wrote a need for a target in a period shorter than the annual (eg monthly target, 3 monthly, or semester / 6 months) to break the annual target [8]. The target in the Balanced Scorecard can mean something that represents the result of measurement of performance indicators for each desired target achievement with adjusted based on duration [6]. The determination of these targets will provide an overview of the results to be achieved, as well as information on budgeting calculations associated with the target magnitude indicated.

\section{Develop Ranking and Performance Contract}

Preparation of contract performance by drafting cascading of the Balanced Scorecard at the organizational level to the Balanced Scorecard in the lower level. The cascading process is a communication medium between the goals and strategies of the highest levels of the organization to the lower levels of the organization. Relations respective goals and strategies from top to bottom can be created by closely and more technically translated to the level of subordinates.

The cascading process is done by lowering the level of Balanced Scorecard The Balanced Scorecard organization into lower-level positions. Each new level reduction resulted in a more technical scorecard, but still has a significant contribution to the scorecard that is on it. Cascading between Balanced Scorecard Strategy Map and Scorecard at once [4]. Penjenjangan well as to map strategies and scorecards possibility of creating a new complexity due to the many questions that have sprung up at every level of the organization. By creating a strategy map then goals and performance indicators into the organizational level below the level would be more effective to ensure that all available resources are used to achieve the same strategic objectives.

Learning and Growth perspective in public organizations is usually conducted or coordinated by the Division of Administrative Bureau or sub-section of the General Secretariat Department/ Agency and not carried out independently by the respective technical areas. Thus, the perspective is more like a job together that although it can be carried out independently in each technical area. But the effects of such coordinators Subdivision Administration/ Public and Civil Service. Thus in setting cascading Balanced Scorecard average of all sections and subsections using the same targets and indicators. The differentiator practice only on the target, wherein when the level of the target organizations considers the entire organization as a whole. The existence of the hierarchy, around the strategic objectives, to be achieved in a more workable organization technically with by all components within the organization. Each officer to be responsible for the achievement of organizational objectives corresponding portions and their respective authority.

Performance trees generally only include strategic objectives and Key Performance Indicators that are directly related to the main tasks and technical functions of the organization so that the cascading process is limited to such matters. This causes the tree 
does not load the performance of strategic objectives and performance indicators per echelon is complete, only the goals and performance indicators that are considered most important. Post applied it all structural contained shall implement them mobilize all available resources. One way to control the performance of subordinates should be attached to the supervision instrument Performance Contract. Performance contracts usually contain information about officials Person in charge, Direct supervisor in charge of strategic objectives, performance indicators are carried along with the target performance.

Overall the performance contract will provide information on who the responsible officials and to whom the contract is agreed. In addition to the strategic objectives, indicators and performance targets are agreed upon, even the program and the number of available funds should be included in the performance contract. Once both parties sign the contract officially then both parties must complete their respective tasks following the role that has been agreed upon. The existence of this Performance Agreement for enforcement officials will show what leadership expectations and responsible charged, while the leaders will show any support needed by subordinates as well as how to assess the performance of subordinates after the implementation of the budget is completed [9].

\section{Programming and Activities required}

With the linkage between the targets and indicators of the level of organization at the level of parts as mentioned above, the right performance indicators will give you a hint of what programs and activities to be implemented to succeed with the effective achievement of targets. Appropriate programs and activities that will provide the maximum effect in achieving strategic objectives. The programs and activities can be established by considering the strategic goals and performance indicators of the level of organization or program level as a base section and subsection level of performance indicators as the basis of activities. Similar strategic objectives can be put together in the same program. The program will act as the elaboration of strategic objectives and provide quantitative values and qualitative data to evaluate the achievement of strategic objectives $[7,10]$.

Their specifications duties and functions of each part, the compiled program should be uniquely associated with respective sections. In addition to the unique program that can be utilized for lean planning for programs created would be less. The program can merge several similar strategic objectives into one kind of program because later be broken again in the technical activities. Strategic objectives at the level of subsections because of the technical nature of that activity so that it can directly translate strategic objectives subdivision level. The activities can be arranged according to the number of strategic objectives which will certainly provide a direct influence on the achievement of strategic targets upper level. But usually a fairly limited number of activities due to an insufficient amount of funds. Only activities which are based on ideal conditions strategic objective would be to give effect to the achievement of targets, both at the grassroots level and the level of organization, and with the identification of activities that are considered "ideal" would be easier to maintain these activities if there are cutting the number of activities or cutting a number budget.

SAKIP program selection has been determined directly by the South Kalimantan provincial Bappeda, so SKPD can only choose from the available programs by considering the program linkages with activities that are organized. However, for the activities to be proposed based on the needs of each SKPD. Organization Bureau itself in 2018 had a total of 2 courses and a 9 activity. This number is decreasing compared with previous years wherein 2016 there were 2programand 27 activities. Generally, there are some differences in management SAKIP and Balanced Scorecard Strategy Map are:

Table-3: Differences Tree Performance and Strategy Map

\begin{tabular}{|l|l|}
\hline \multicolumn{1}{|c|}{ performance trees } & \multicolumn{1}{|c|}{ map Strategy } \\
\hline $\begin{array}{l}\text { Strategic Objectives are based on the duties and functions and } \\
\text { concerning the strategic targets on the top level. }\end{array}$ & $\begin{array}{l}\text { The strategic goal is based on the Balanced Scorecard } \\
\text { perspective and the perspective of a public organization which } \\
\text { peaks at Customer Perspective. }\end{array}$ \\
\hline $\begin{array}{l}\text { The number of strategic objectives for each officer a little more, } \\
\text { because it only refers to the duties and functions of the } \\
\text { respective positions }\end{array}$ & $\begin{array}{l}\text { The number of strategic objectives more, for each position to } \\
\text { consider the four perspectives in formulating strategic } \\
\text { objectives. }\end{array}$ \\
\hline $\begin{array}{l}\text { The causal link arranged vertically and connected directly only } \\
\text { on goals that exist above and below it. }\end{array}$ & $\begin{array}{l}\text { The causal relationship applies to all related targets, both } \\
\text { between perspective and in the same perspective. }\end{array}$ \\
\hline $\begin{array}{l}\text { Contains strategic target of several levels of the organization, } \\
\text { usually composed of the strategic objectives of the second } \\
\text { echelon to echelon IV }\end{array}$ & $\begin{array}{l}\text { Containing only 1 level strategic objectives for the organization, } \\
\text { this is due to the strategy map of each level must contain four } \\
\text { perspectives that exist. }\end{array}$ \\
\hline $\begin{array}{l}\text { Cascading process for organizational performance directly } \\
\text { reflected in the tree because it describes the overall performance } \\
\text { hierarchy. }\end{array}$ & $\begin{array}{l}\text { The cascading process has not been seen in the first Roadmap } \\
\text { since it takes some of the strategy maps in the Balanced } \\
\text { Scorecard cascading process. }\end{array}$ \\
\hline \multicolumn{2}{|l}{} \\
\hline
\end{tabular}




\section{Performance Measurement}

Performance measurement, data, and assumptions in measuring the performance to be something very important. This is due to the performance of the government as public organizations often can not be measured only from a quantitative form, but often necessary in the form of qualitative measurements depend on the performance object [8]. Therefore, as a measure of performance indicators to measure the performance targets to be something very important about the measurement of organizational performance. The performance indicators that can be measured is a must, both quantitatively and qualitatively. In addition to measurable indicators of performance targets also need to have a valid data source before it can be determined to be an indicator. It should be noted that when the performance measurement.

Bureau of Organization for the preparation of the performance tree besides composing and performance goals, as well as to develop indicators of performance for each strategic objective. Selected Indicators compiled by the SMART criteria as mentioned above. In practice, the strategic objectives and performance indicators to be differentiated based on the level of office. Targets and performance indicators at the level of echelon I and II using shaped indicator "outcomes". Echelon III can use the indicator "outcomes" or "output", while echelon IV can be described by the indicator "output". The fundamental difference in the indicator "output" to 2 levels are indicators of "output" for output echelon III is "essential" that is "results" directly from the implementation of the program or the results of the implementation of activities.

Criteria goals and performance indicators of each echelon that facilitate the leveling process, for all the output produced by the direct performance of echelon IV will deliver results and contribute to the performance outcomes or outputs important in echelon III. Furthermore, all the important outcome or output echelon III will be the basis for calculating the performance measure echelon II, because of the nature of outcome indicators that require further measurement in determining the outcome achievement. Each indicator is composed of performance, then performance measurement next step is the provision of accurate performance data and valid. Organization Bureau has several kinds of data sources on stage this performance measurement. For the fourth echelon of performance measurement which incidentally is a direct output of the activity is a direct data source echelon IV which each calculates output PPTK activities undertaken or to be responsible for the activities that have been prepared. Similarly to the third echelon that performance is more affected by the implementation of activities and programs, so that the data source is the same as echelon IV, but the measurement needs to be further processed following the indicators used.

Echelon II, the performance indicators used are outcome indicators and are associated with SKPD or other agencies that source of data to measure the performance must be observed strictly. For the 2018 performance indicators that have been defined, two of the three indicators are still using internal data sources, the indicator "Percentage of the Region with an effective institutional "and" The average value of the regional Community Satisfaction Survey ". Both of these indicators using data from the field of Institutional and art of management and public services in measuring achievement. As for echelon III, both indicators are also using the basic data output further activities to be further processed for use in describing the performance outcome echelon II. In indicator"The average value of the regional Community Satisfaction Survey" even needs to wait for a report from the Public Satisfaction survey of all institutions of Public Service providers in the environment of South Kalimantan provincial government before it can be recycled.

One final indicator "Percentage of Government Performance Accountability System (SAKIP) of the Region with a minimum grade $B$ " requires a data value SAKIP SKPD evaluation carried out by the Inspectorate of South Kalimantan province. This led to measure the performance of the indicator should wait for the completion of the evaluation process Inspectorate. However, in general, this indicator is easier to get the data achievements, because the evaluation process SAKIP SKPD by Inspectorate is an annual event, and this data will provide an overview of how the coaching process SAKIP SKPD by the Bureau of the Organization as assessed objectively by SKPD examiner official (Inspectorate). regulations residential Regulation No. 29 The year 2014 on Government Performance Accountability System mentioned that implemented performance measurement by comparing the data with the performance realization achievement of performance targets. But regulation of the Minister of Administrative Reform and Bureaucratic Reform of the Republic of Indonesia Number 53 of 2014 Regarding Guidance Agreement Performance, Performance Reporting, and Procedures Review and Planning Statements Government Performance in more detail mentioned that in addition to comparing with annual targets, performance measurement also needs to be carried out by comparing:

1. Performance achievements with the achievements performance for several years back, especially with the RPJMD year period. This comparison will give you an idea of how the progressive achievement of organizational performance, whether the slowdown, constant or accelerating.

2. The gains of the mid-term targets (target 5 years), so that visible progress has been achieved until the 
current year compared with the targets that should be achieved in 5 years or RPJMD period. By comparison will be the visible position of the gains towards the medium-term target, to take measures to anticipate the result of the measurement, whether to remain in the existing conditions or the need to further improve faster performance.

3. Performance achievements with achievements or national standards if applicable. This comparison is to show the position of the performance of SKPD and Local Government with RPJMN performance, especially if it has the same indicators with RPJMN. Thus, it will be known how the contribution of South Kalimantan Province in the achievement of national targets.

In addition to using the national standard next step is to compare the actual performance with the performance achievements of nearby area / regional neighbors. Thus, the South Kalimantan province will compare the gains of the local government or local government performance SKPD with performance or SKPD in the province of East Kalimantan, Central Kalimantan, West Kalimantan, and North Borneo. The existence of this comparison will provide a holistic view where the South Kalimantan position, when compared with the achievements of the National and Regional, so that performance measurement will be more objective because of high achievement, is not necessarily seem high when compared to the national or regional basis, or vice versa. The performance measurements carried out at least once a year and can be done monthly or quarterly, depending on the needs of the organization.

\section{Performance Reporting}

Reporting of performance is a continuation of the performance measurement process. Performance measurements that have been implemented should be reported to stakeholders so that performance measurements can be evaluated further. Performance Report becomes a tool to provide accountability regarding performance reported, about how the process of achievement of the performance until the time of reporting implemented, obstacles and challenges encountered, about the successes and failures and the factors that influence.

Accountability is a term in the process to account for all activities the government implemented in fiscal year heavier in this reporting process. Performance reporting into local government accountability tool and SKPD to the use of available resources and presents the results that have been achieved, both successes and failures. Performance report included the following information:

1. All structural performance measurement in the organization, a good measure of the annual targets, five-year targets, standards/target comparison of national and regional realization.
2. A detailed explanation of the success or failure of that achieved in the achievement of the relevant fiscal year. This explanation contains support achievement of performance (if successful), an inhibitor that causes a failure (if it fails or has not reached the target), actions taken in the previous year related to performance evaluation,

3. An analysis of the use of resources and budgetary support in the achievement of the performance, as well as programs and activities that lead to the success or failure of performance.

4. A brief report on the realization of the budget used for performance following the Performance Agreement.

5. An improvement plan that will be implemented in the organization improve the lack of achievement or improve the performance already achieved in the coming years.

\section{Performance evaluation}

Evaluation of the performance of the organization over the past year South Kalimantan Provincial Inspectorate implemented. The evaluation process carried out in the early years after the performance report submitted by the end of February, and the evaluation results will be announced to all SKPD attended by the Governor of South Kalimantan and all Heads of SKPD. The performance evaluation is focused on the implementation of the internal evaluation of the Organization, formally not part of the required accountability SAKIP but quality. In regards implementation of the activities, Head of Organization always conducting monthly meetings to monitor the implementation of activities and discuss plans for the activities undertaken. At monthly meetings evaluated the activities that have been completed, visible on the implementation of these activities.

The total evaluation conducted after the report is completed performance. The achievement of each strategic goals and performance indicators for all structural, including the achievement of the Organization. Therefore, the Head of Organization held meetings and conducted a thorough assessment of the performance of the Bureau of the Organization. The meeting was conducted in addition to evaluate to plan the implementation of activities for the next fiscal year. The evaluation was conducted by the Head of the gains of the organization, among others, the achievement of the performance of each structural officials. If there is a strategic goal that is still not reached, discussions on how the solution and follow-up are referred to as "debt" performance. The target is to be paid whenever possible

\section{Performance Achievement}

Achievement of the performance became a benchmark for the success of structural officials. With the attainment of appropriate targets and sufficient budget absorption, an official can be said structural achievement. Thus, if the achievement of performance 
can be achieved approaching or up to $100 \%$, then the implementation of programs and activities by structural officials, in general, can be considered good. In 2017, the average achievement of Head of Organization is $100.75 \%$ of the 3 strategic goals and three indicators of performance, which means that his achievement in each of the strategic objectives already reached the target and even exceed the target. For echelon III officials reached an average of more than $100 \%$ performance consisting of three parts. Furthermore, the gains for the echelon IV officials quite varied with average achievement between $80 \%$ - 90\%. (Source of the Year Organizing Bureau Performance Report 2017). Thus for the Bureau of the Organization itself generally has successfully implemented with good performance and tends to get satisfactory results.

Problems failure to achieve most performance lies in echelon IV officials. This may be where the echelon IV is spearheading the implementation of programs and activities, which sometimes is not all programs and activities implemented as planned, particularly in the event of changes in policy or external conditions that lead to delays and even cancellations of planned activities. In spite of various constraints faced by echelon IV, all goals achieved though not yet fully reached the target.

Average structural organization Bureau officials plan to pay off debts that have not been successfully achieved performance in the next fiscal year. But often it hindered their budget reductions made by the Planning Agency. With the reduction of the budget usually step taken was to reduce its performance targets becomes smaller. It is in the short term is not too significant influence, but in the medium and long term will affect the performance targets in the Strategic Plan and RPJMD, even RPJMN. However, due to the lack of rules that regulate reward and punishment related to the achievement of performance led to the achievement of the performance impressed left as it is.

\section{SAKIP impact on Performance Improvement Organization Bureau Regional Secretariat of South Kalimantan Province}

\section{Customer perspective}

Customer Perspective into perspective Balanced Scorecard major public organizations. This is because the main purpose of public organizations is to serve society and utilize all resources. Mission accomplishment can not be measured by financial and administrative responsibilities. But determined to whom services are provided and how to provide these services with the best. This perspective emphasizes the translation of the mission to be objective and targets based on subscribers/customers of each organization. Based on the survey results revealed that the performance of the customer's perspective on the whole thing Organization Bureau is related SKPD. 2016 and
2017 the increase in the achievement of the organization's performance, both at the level of the second echelon, echelon III and IV. This performance improvement was seen in the Performance Reports documents prepared by the Bureau of the Organization. The improved performance illustrates the improved performance on the customer's perspective because the whole performance listed in general is a depiction of the customer's perspective.

\section{Financial perspective}

The financial perspective is the most important perspective for-profit organizations, but not so with public organizations. Financial perspective for public organizations to put forward how the budget is used as effectively and efficiently as possible in carrying out programs and activities, in other words, public organizations prioritize how to spend the budget well rather than how to increase revenue. A budget that can not be absorbed by the Bureau of the Organization, in general, is still at the exposure limits. Besides, it is also due to the reason the return of the budget is still acceptable and very commonplace. Unlike the case, if the return of the budget due to non-performance of activities, which of course will affect the performance. Organization Bureau implement budgeted activities.

\section{Internal Process Perspective}

This perspective aims to formulate objectives in improving the quality of the organization to regulate in detail all the internal processes within the organization in support of the achievement of other perspectives. Organizations with solid internal processes will be able to provide the best service to their customers. One of the issues faced by the Indonesian government, both central and local levels is the lack of effective management systems are implemented so that all activities of the bureaucracy was impressed at will. Standard Operating Procedures are not raw, yet effective administrative system, lack of innovation, and other issues. Handalan lack of public organizations in responding to the times make the internal process perspective is indispensable for services provided to the perceived benefits. SOP activities were arranged was prioritized for service activities or who deal directly with customers/consumers, so some administrative SOPs are planned to be prepared unfinished set. But armed with the SOP that has been prepared, the Bureau remains Organizations can implement activities and provide advisory services to SKPD that relate directly to the Bureau of the Organization. The SOP is to provide a standard implementation and customer satisfaction to the Organization Bureau. Organization Bureau still can carry out activities and provide advisory services to SKPD that relate directly to the Bureau of the Organization. The SOP is to provide a standard implementation and customer satisfaction to the Organization Bureau. Organization Bureau still can carry out activities and provide advisory services to 
SKPD that relate directly to the Bureau of the Organization. The SOP is to provide a standard implementation and customer satisfaction to the Organization Bureau.

\section{Learning and Growth perspective}

Human Capital or Human Resources is an important factor in the organization. The existence of competent human resources to deliver better organization. Competent human resources are not necessarily obtained instantaneously but needs to be developed from existing human resources within the organization. But unfortunately improving the quality of human resources becomes a matter of less taken seriously by the organization, whether public or private. HR placed in a position to have the right skills to be able to streamline its title and of course promising optimal performance. Conversely, when the skill and ability to occupy a position of human resources are still relatively less or not following the work requirements will waste a lot of resources.

At the Organization Bureau still found that improving the quality of human resources is still not full attention. Budgeting is provided only budgeted to meet the demand if there are civil servants who want to follow the training. But planning to engage actively in the training of civil servants who held the local government and central government did not exist. On the other hand, the average civil servant Organization Bureau did not actively seek information about training/education, unless there is a command to follow. Therefore, the overall performance in this perspective is less successful because they lack good care of personal leadership and human resources available to develop themselves through training and education provided.

\section{Cascading performance}

Penjenjangan proper performance will give the chain reaction on the achievement of performance expected by SKPD. When leveling is done effectively then the entire planning process performance will show the synchronization of performance targets statement to the activities to be implemented. Thus the process of achievement of performance carried out by the organization arranged. SAKIP implementation of the local government, all SKPD has compiled the document tree hierarchy Performance performance. Organization Bureau has compiled Trees and performance has made several changes and improvements to continuously improve them. Last perceived is the most nearly perfect leveling by Karo Organization. It is concerned with solving the performance objectives of the local government level to the level of implementation of activities arranged clearly. This certainly shows the planning process performance is quite accurate, with all programs, activities and performance targets at the lowest levels will have a real impact on the achievement of performance at the level above it.

\section{CONCLUSION}

Government Performance Accountability System adopted the Balanced Scorecard concepts, but only general concepts. In planning the performance, especially in the process of leveling performance, there is still a difference, where SAKIP did not use four perspectives used in the Balanced Scorecard. The programs and activities which also has the distinction SAKIP can only select an activity, while the Balanced Scorecard to develop programs and events thoroughly. The process of measuring, reporting, evaluation and monitoring of performance, and achieve similar performance between SAKIP and Balanced Scorecard. In the operation SAKIP, some impacts are visible in the performance management of the Organization, where the customer perspective, Financial perspective and the perspective of internal processes occur significantly improved performance. But the Learning and Growth perspective was still not successful because of the activities to improve the quality of human resources through education and training is still less attention.

\section{REFERENCES}

1. Afifuddin., \& Ahmad, B. (2009). Metodologi Penelitian Kualitatif. Bandung: Pustaka Setia.

2. Afrizal. (2014). Metode penelitian kualitatif: sebuah upaya mendukung penggunaan penelitian kualitatif dalam berbagai disiplin ilmu. PT RajaGrafindo Persada.

3. Burhan, B. (2001). Metodologi Penelitian Kualitatif Aktualisasi Metodologis ke Arah: Ragam Varian Kontemporer. Jakarta: Rajawali Pers.

4. Ibrahim. (2015). Metode Penelitian Kualitatif. Bandung: Alfabeta.

5. Marr, B., \& Creelman, J. (2011). More With Less, Maximizing Value in the Public Sector. Great Britain: Palgrave MacMillan.

6. Niven, P. R. (2008). Balanced Scorecard Step-ByStep for Government and Non Profit Agencies (Second Edition). USA: John Wiley \& Sons, Inc.

7. Mulyadi. (2007). Sistem Terpadu Pengelolaan Kinerja Personel Berbasis Balanced Scorecard. Yogyakarta: UPP STIM YKPN.

8. Moeheriono. (2012). Indikator Kinerja Utama (IKU): Perencanaan, Aplikasi dan Pengembangan. Jakarta: RajaGrafindo Persada.

9. Wibowo. (2016). Manajemen Kinerja, Edisi keempat. Jakarta: Rajawali Pers.

10. Hannabarger, C., Buchman, R., \& Economy, P. (2007). Balanced Scorecard Strategy For Dummies. Indianapolis: Wiley Publishing, Inc. 